Supporting Information

\title{
Rapid and controllable formation of robust superwettable microchips by click reaction for efficient o-phthalaldehydes
}

\section{and glucose detection}

Jianying Huang ${ }^{a}$, Hui Yang ${ }^{a, b}$, Jiajun Mao ${ }^{a}$, Fang Guo ${ }^{b}$, Yan Cheng ${ }^{b}$, Zhong Chen ${ }^{c}$, Xiaoqin Wang ${ }^{b}$, Xiao Li $i^{a}$,Yuekun Lai ${ }^{a, b^{*}}$

${ }^{a}$ College of Chemical Engineering, Fuzhou University, Fuzhou 350116, P. R. China.

${ }^{b}$ National Engineering Laboratory for Modern Silk, College of Textile and Clothing Engineering, Soochow University, Suzhou 215123, P. R. China.

${ }^{\mathrm{c}}$ School of Materials Science and Engineering, Nanyang Technological University, 50 Nanyang Avenue, Singapore.

Corresponding Authors E-mail: yklai@fzu.edu.cn

Number of Pages: 8

Number of Figures: 14 


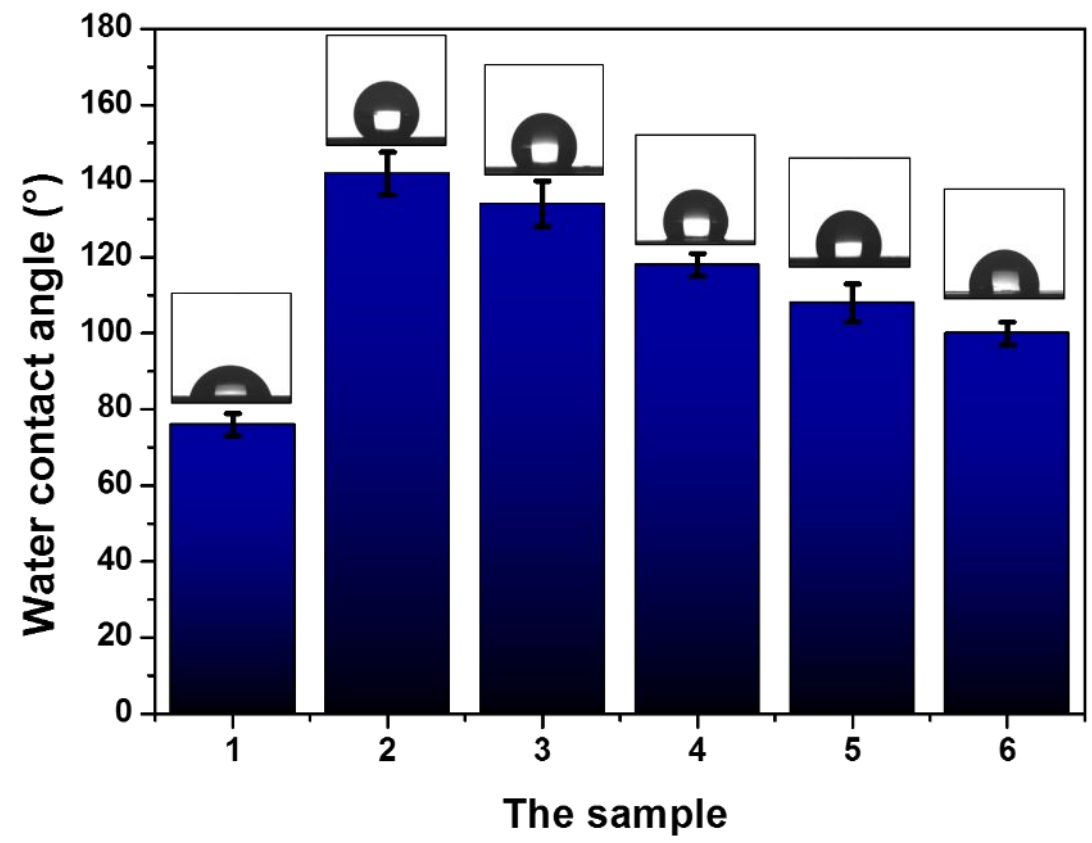

Figure S1. The WCA of sample 1: smooth film. Rough PM-EDMA films: 24 wt.\% PM, 16 wt.\% ED with different proportions of 1-decanol and cyclohexanol, sample 2: 1-decanol (60 wt.\%), sample 3: 1-decanol (50 wt.\%) and cyclohexanol (10 wt.\%), Sample 4: 1-decanol (40 wt.\%) and cyclohexanol (20 wt.\%), sample 5: 1-decanol (20 wt.\%) and cyclohexanol (40 wt.\%), sample 6: cyclohexanol (60 wt.\%). 

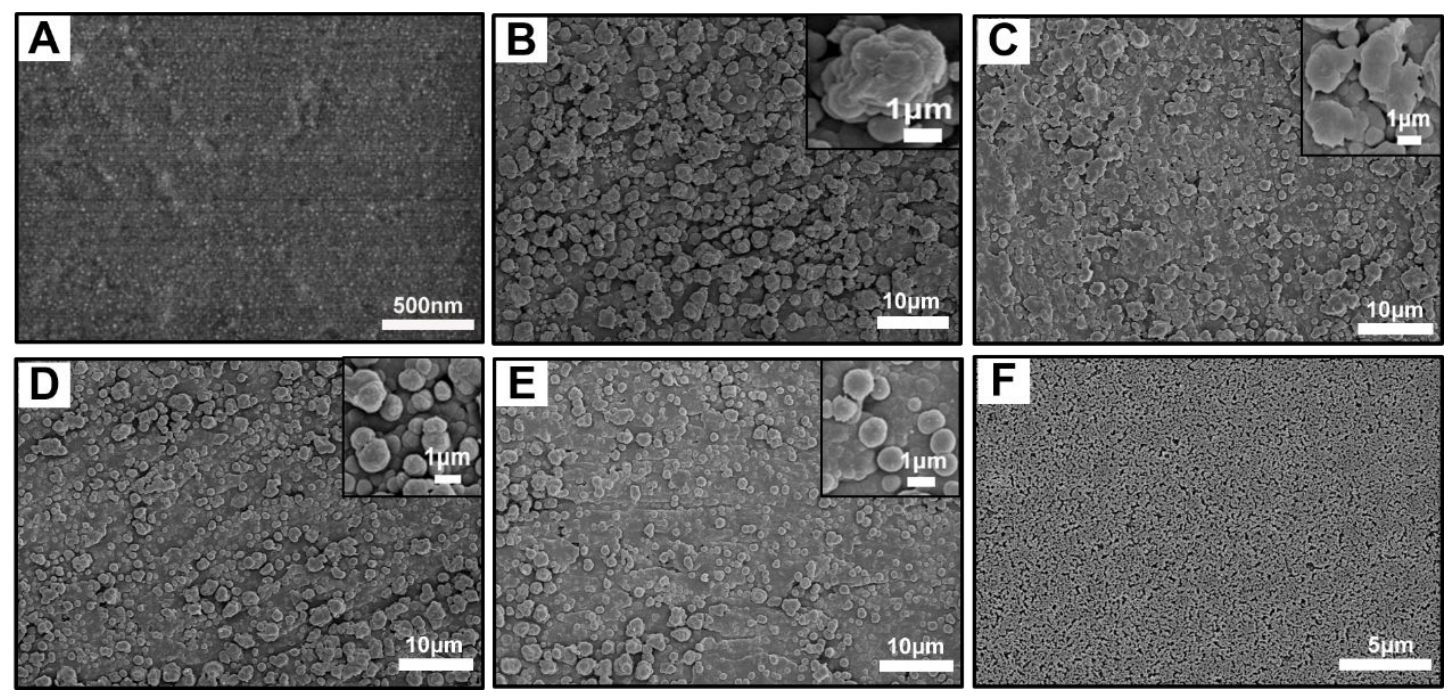

Figure S2. The SEM images of smooth film (A). Rough PM-EDMA film: 24 wt.\% PM, 16 wt.\% EDMA with different proportions of 1-decanol and cyclohexanol, (B) 1-decanol (60 wt.\%), (C) 1-decanol (50 wt.\%) and cyclohexanol (10 wt.\%), (D) 1-decanol (40 wt.\%) and cyclohexanol (20 wt.\%), (E) 1-decanol (20 wt.\%) and cyclohexanol (40 wt.\%), (F) cyclohexanol (60 wt.\%).

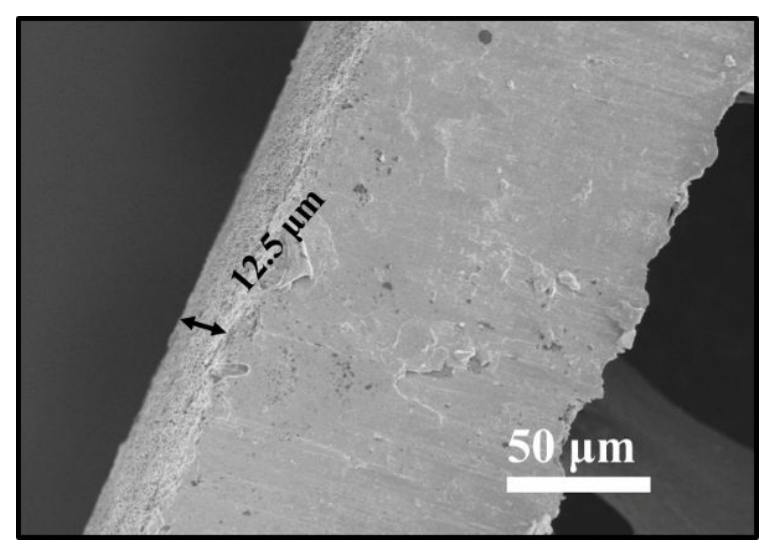

Figure S3. Cross-sectional SEM image of $12.5 \mu \mathrm{m}$ PM-EDMA film. 

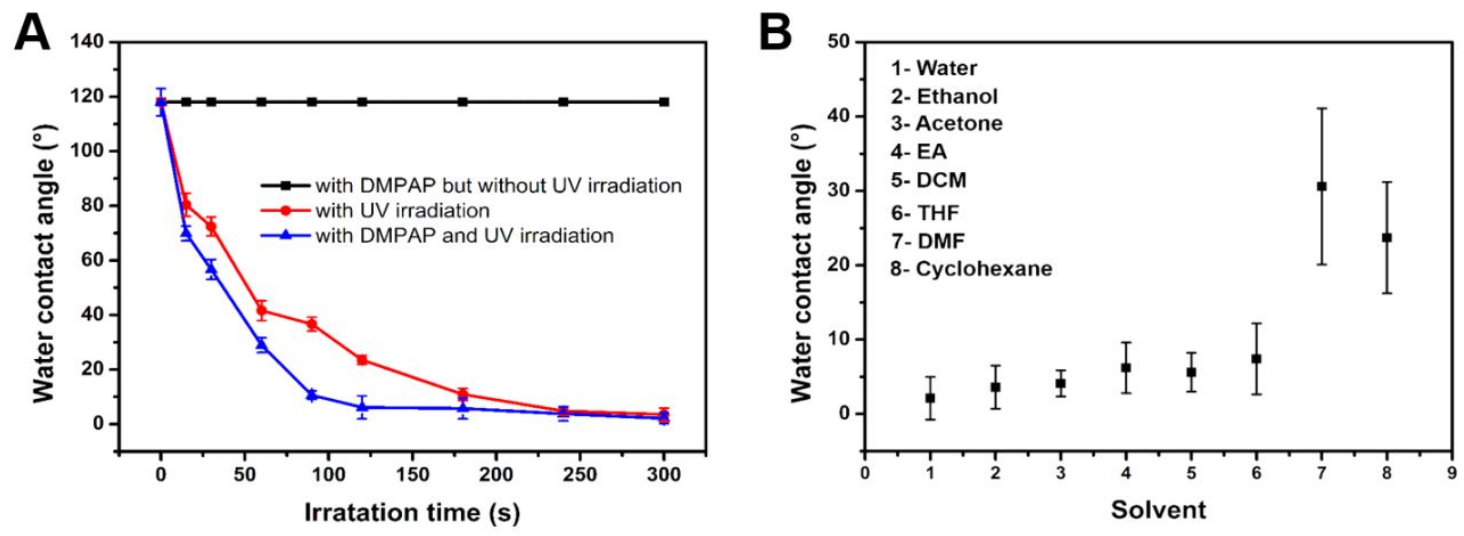

Figure S4. (A) The WCA of PM-EDMA film modified with 2-mercaptoethanol under the different reaction conditions. (B) WCA of PM-EDMA film functionalized with 2mercaptoethanol dissolved in different solvents.

\section{Superhydrophilic sample}

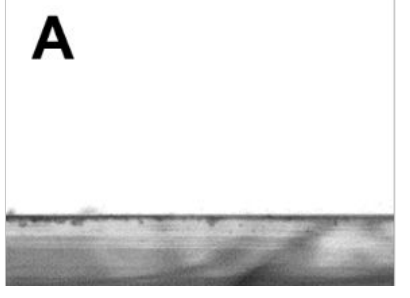

PM-EDMA film Superhydrophobic sample

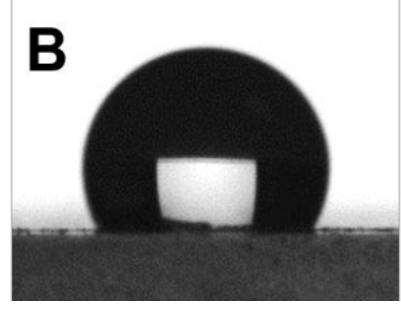

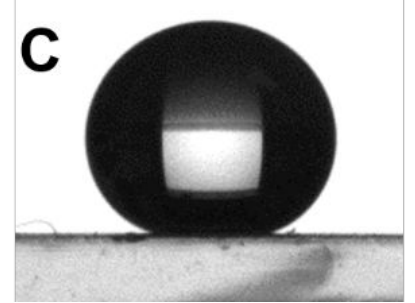

Figure S5. The WCA images of superhydrophilic sample (A), PM-EDMA film (B) and superhydrophobic sample on the glass substrate. 


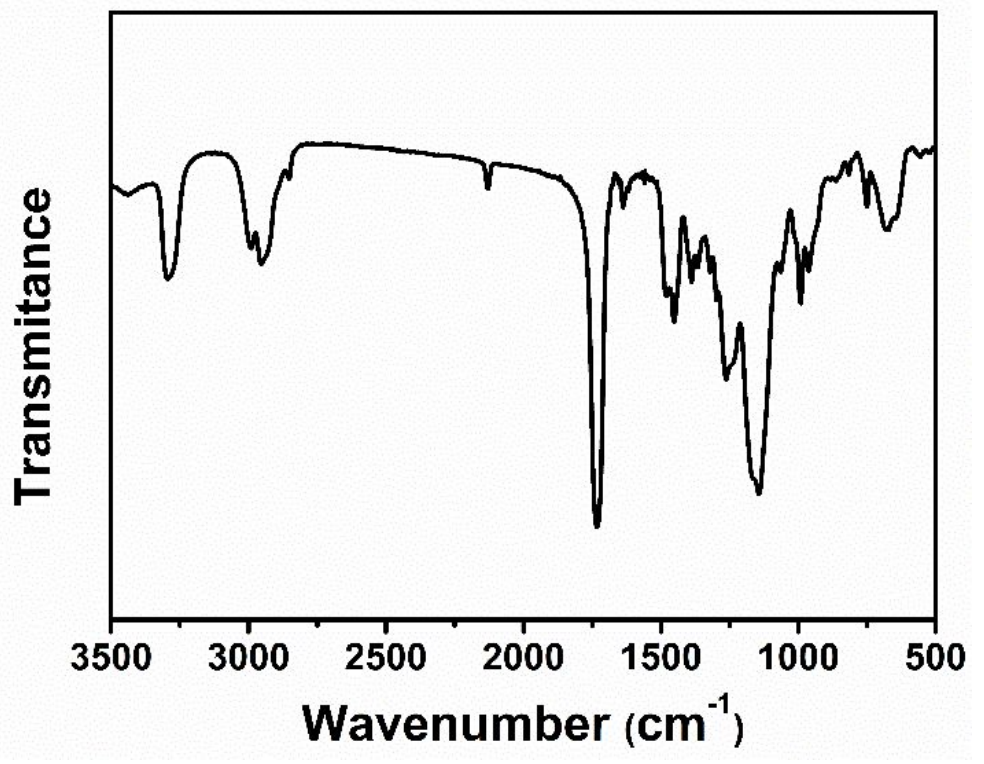

Figure S6. The FTIR of the PM-EDMA film.

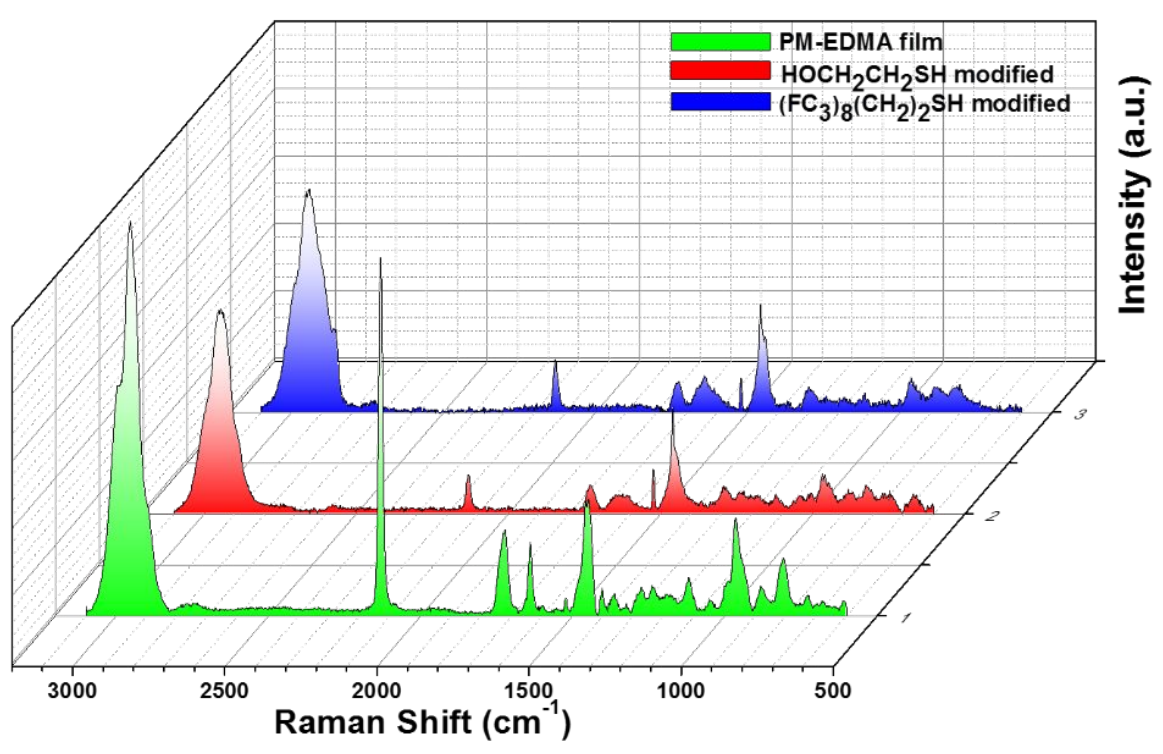

Figure S7. The Raman spectra of PM-EDMA film (green), superhydrophilic sample (red) and superhydrophobic sample (blue). 


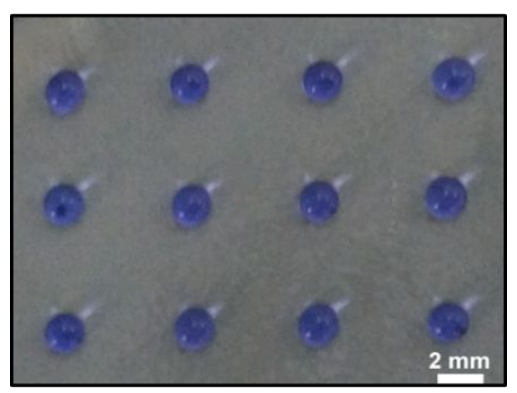

Figure S8. The optical photograph of $2 \mu \mathrm{L}$ acid blue droplets were distributed onto the superhydrophilic dots of the prepared superwettable micropattern.
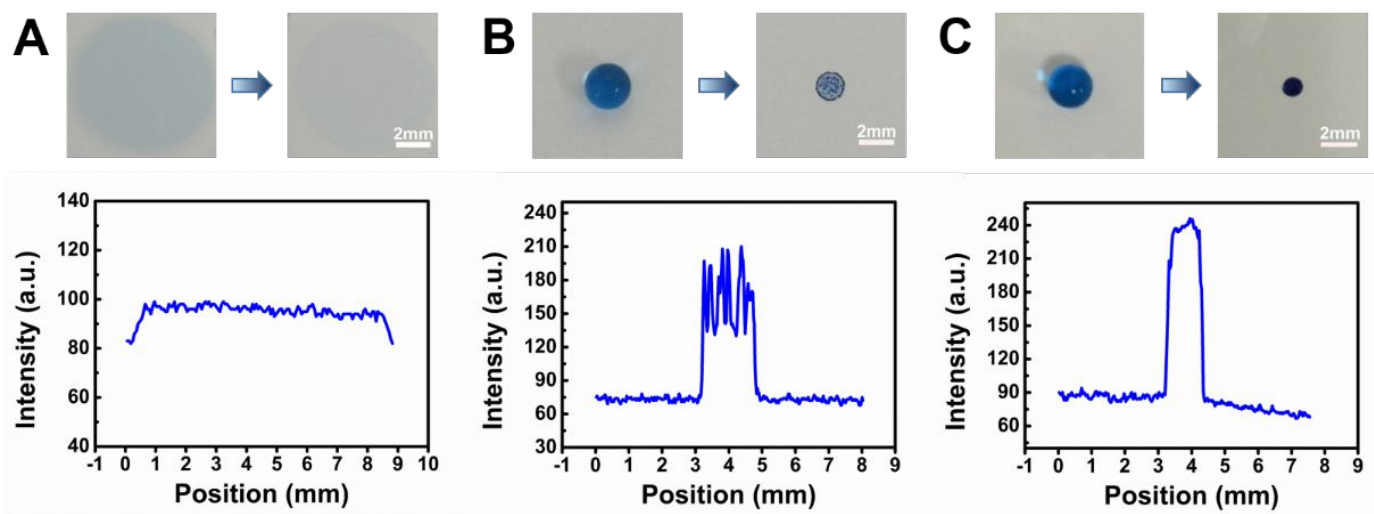

Figure S9. The optical images of acid blue solution $(2 \mu \mathrm{L})$ before and after evaporation and the intensity analysis of deposit spots on the superhydrophilic sample (A), superhydrophobic sample (B) and superwettable micropattern (the diameter is $1 \mathrm{~mm})(\mathrm{C})$.

$10^{-7} \mathrm{~mol} / \mathrm{L} \quad 10^{-6} \mathrm{~mol} / \mathrm{L} \quad 10^{-5} \mathrm{~mol} / \mathrm{L} \quad 10^{-4} \mathrm{~mol} / \mathrm{L} \quad 10^{-3} \mathrm{~mol} / \mathrm{L} \quad 10^{-2} \mathrm{~mol} / \mathrm{L}$
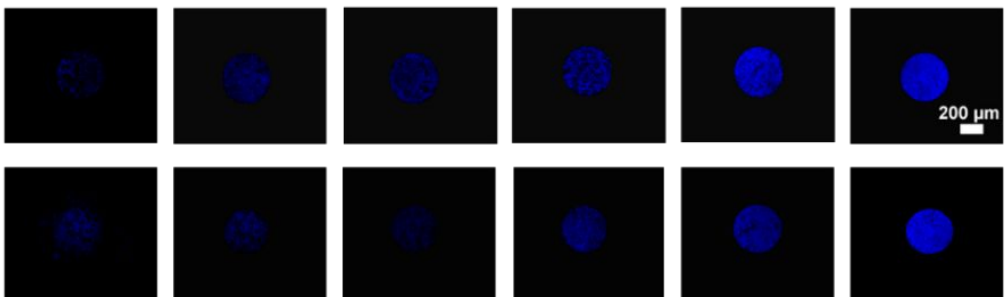

Figure S10. The fluorescence image and intensity of OPA on the microchip after water drop test. 


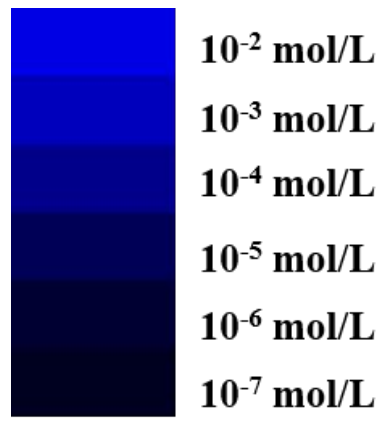

Figure S11. The standard color chart of different OPA concentration.

\begin{tabular}{|c|c|c|c|c|c|c|c|c|c|c|c|}
\hline & $0 \mathrm{~min}$ & $2 \min$ & $4 \min$ & $6 \mathrm{~min}$ & $8 \mathrm{~min}$ & $10 \mathrm{~min}$ & $12 \mathrm{~min}$ & $14 \mathrm{~min}$ & $16 \mathrm{~min}$ & $18 \mathrm{~min}$ & $20 \mathrm{~min}$ \\
\hline $50 \mathrm{mM}$ & $\theta$ & $C$ & 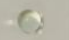 & 0 & c) & 0 & (6) & 6 & c. & 0 & 0 \\
\hline $20 \mathrm{mM}$ & 6 & 6 & 5 & 6 & 6 & 6. & e. & e & Q & e. & Q \\
\hline $10 \mathrm{mM}$ & 6 & 5 & 6 & 6 & 6 & 2 & 8 & 8 & 2. & B. & a \\
\hline $8 \mathrm{mM}$ & 2 & 2 & 3 & 3 & b & 3 & b & 3 & b & b & D \\
\hline $4 \mathrm{mM}$ & 2 & C. & a & $\theta$ & $\sigma$ & 6 & a & c & 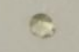 & c. & $\theta$ \\
\hline $2 \mathrm{mM}$ & $\sigma$ & \% & $\sigma$ & $\sigma$ & 6 & 6 & 6 & $\sigma$ & $\sigma$ & 6 & $\sigma$ \\
\hline
\end{tabular}

Figure S12. The colorimetric photographs of different concentration glucose droplet every 2

$\min$.

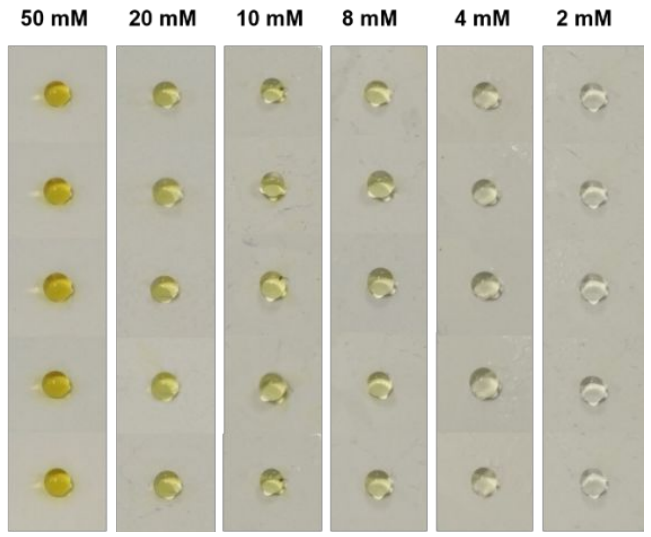

Figure S13. The optical photographs of repeated detection of glucose with different concentrations. Each row represents one test; six tests are shown. 


$50 \mathrm{mM}$
$20 \mathrm{mM}$
$10 \mathrm{mM}$
$8 \mathrm{mM}$
$4 \mathrm{mM}$
$2 \mathrm{mM}$
$0 \mathrm{mM}$

Figure S14. The standard color chart of different glucose concentration. 